Supporting Information for

\title{
A Tetracarboxylate-Bridged Dicopper(II) Paddle-Wheel-Based 2-D Porous Coordination Polymer with Gas Sorption Properties
}

\author{
Dong-Xu Xue, Yan-Yong Lin, Xiao-Ning Cheng, and Xiao-Ming Chen* \\ MOE Laboratory of Bioinorganic and Synthetic Chemistry, School of Chemistry and Chemical \\ Engineering, Sun Yat-Sen University, Guangzhou 510275, China \\ E-mail: cxm@mail.sysu.edu.cn
}

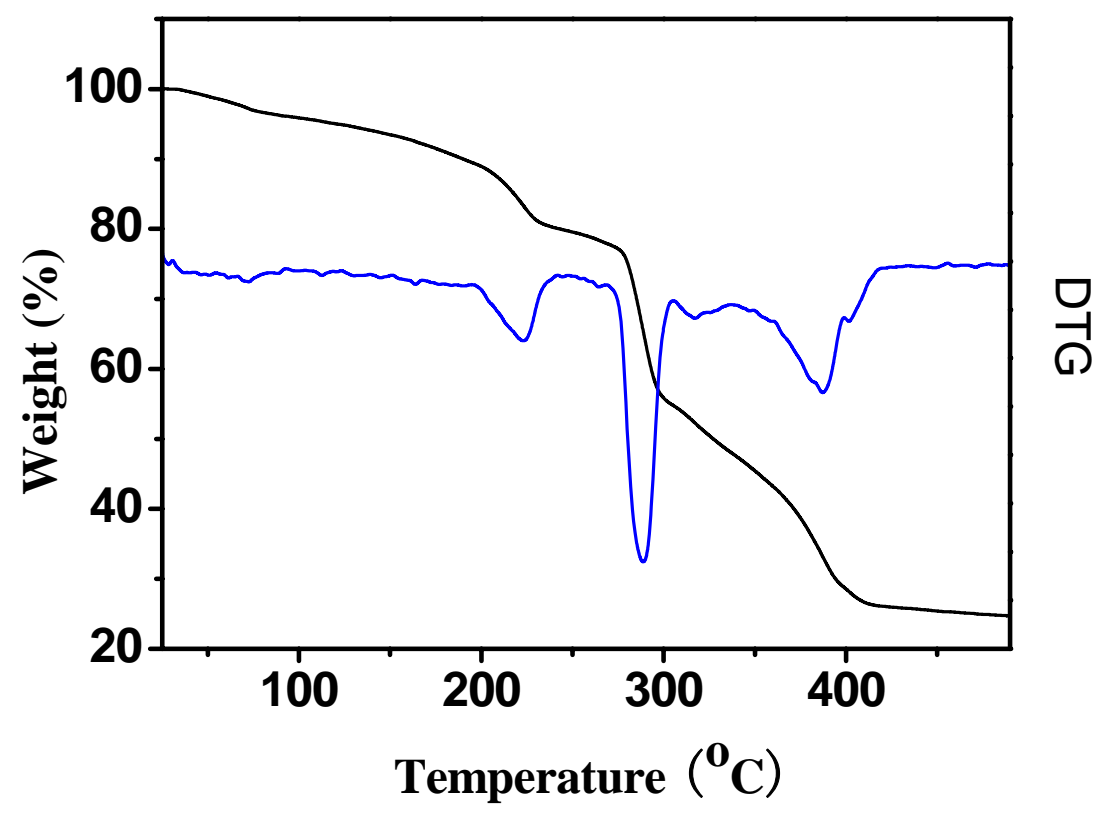

Figure S1. TGA plot of $\mathbf{2} \cdot \mathrm{g}$ recorded under an $\mathrm{N}_{2}$ atmosphere. 


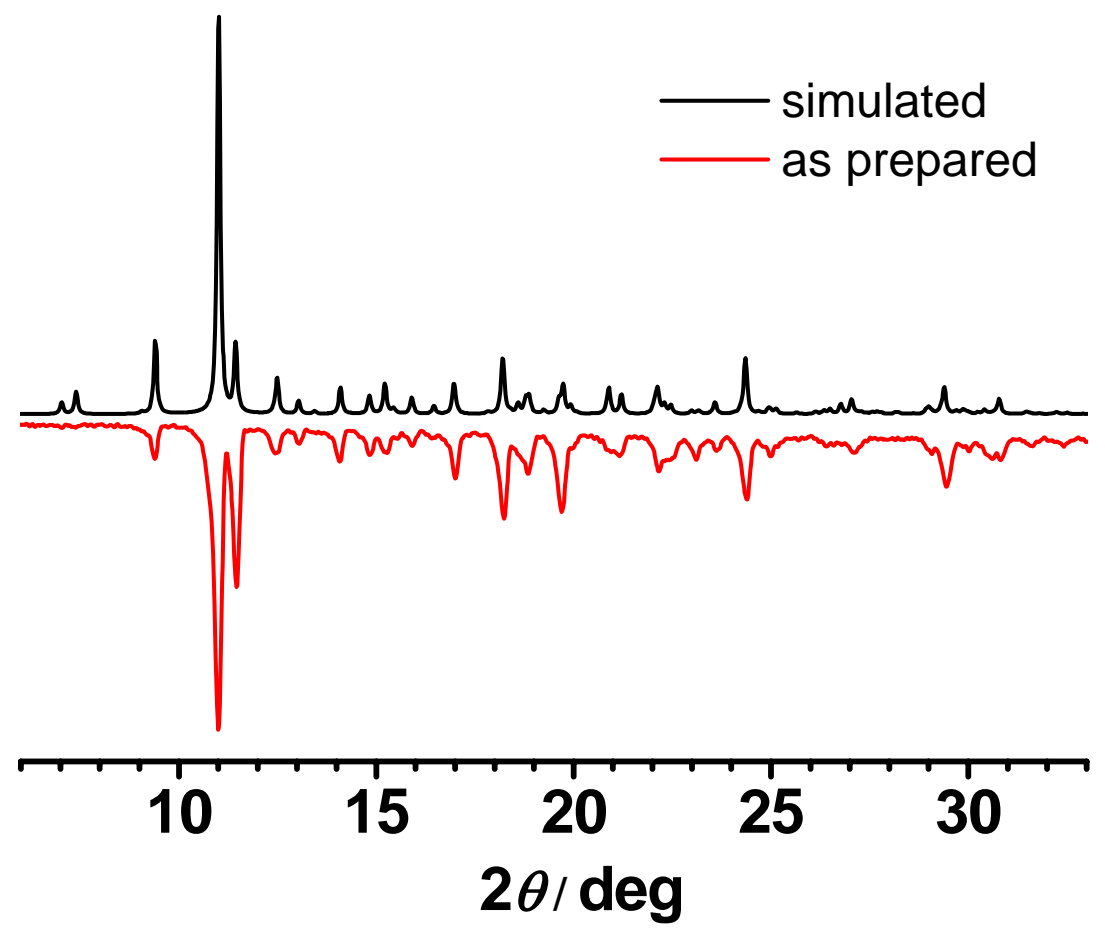

Figure S2. XRPD patterns of 2.g simulated from the X-ray crystal structure (black) and the as-prepared material (red).

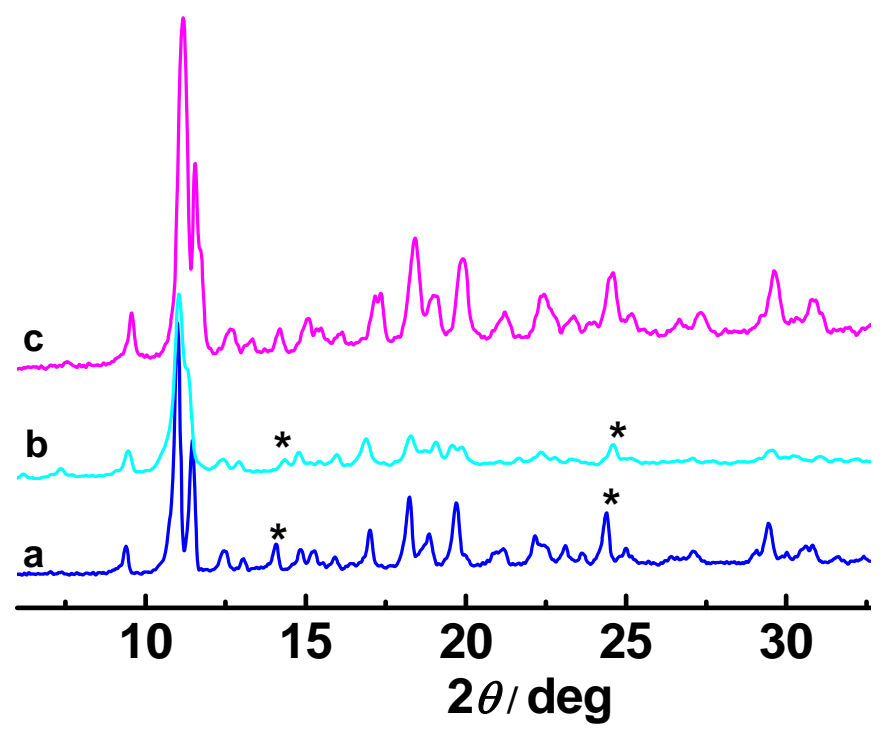

Figure S3. XRPD patterns of (a) as-prepared microcrystalline sample of 2·g, (b) 2 obtained by drying in vacuo for 12 hours at $393 \mathrm{~K}$, and (c) a solid isolated after immersion of $\mathbf{2}$ in the mixture of dmf/ethanol/water (1:1:1) for 24 hrs. The asterisks label the shifted peaks. 


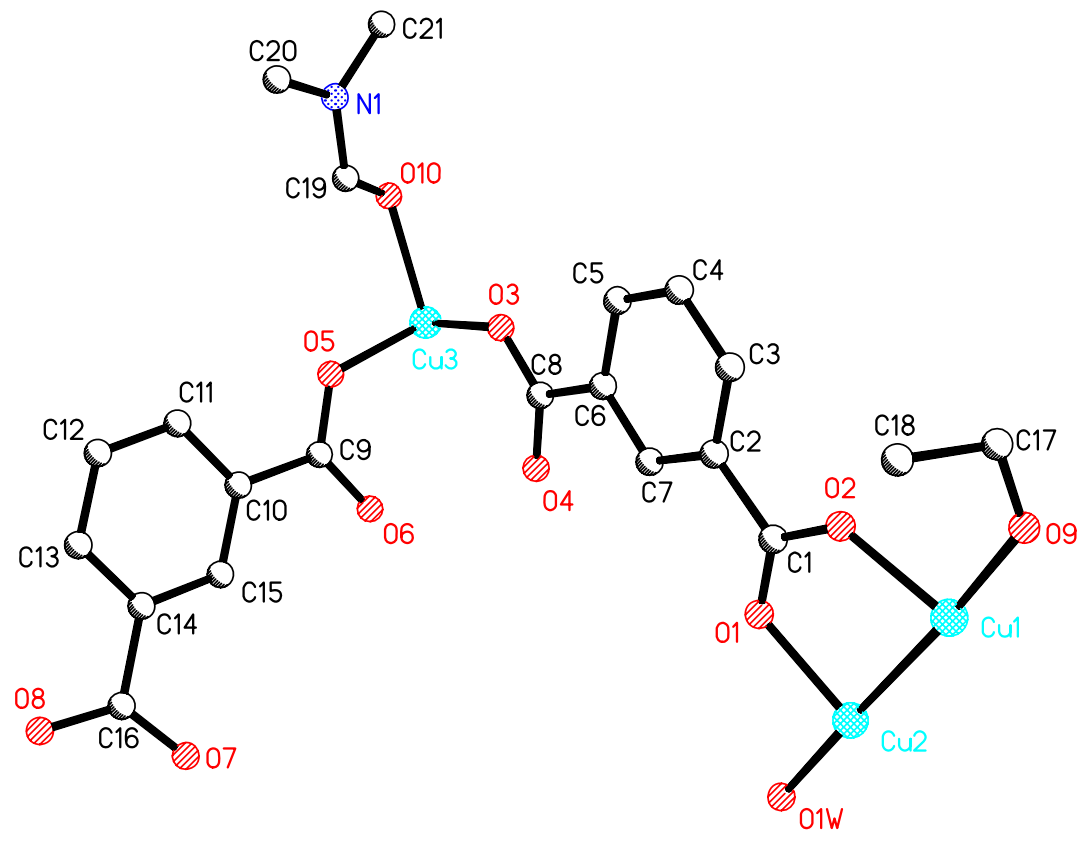

Figure S4. The asymmetric unit in 2·g excluding lattice disordered solvent molecules.

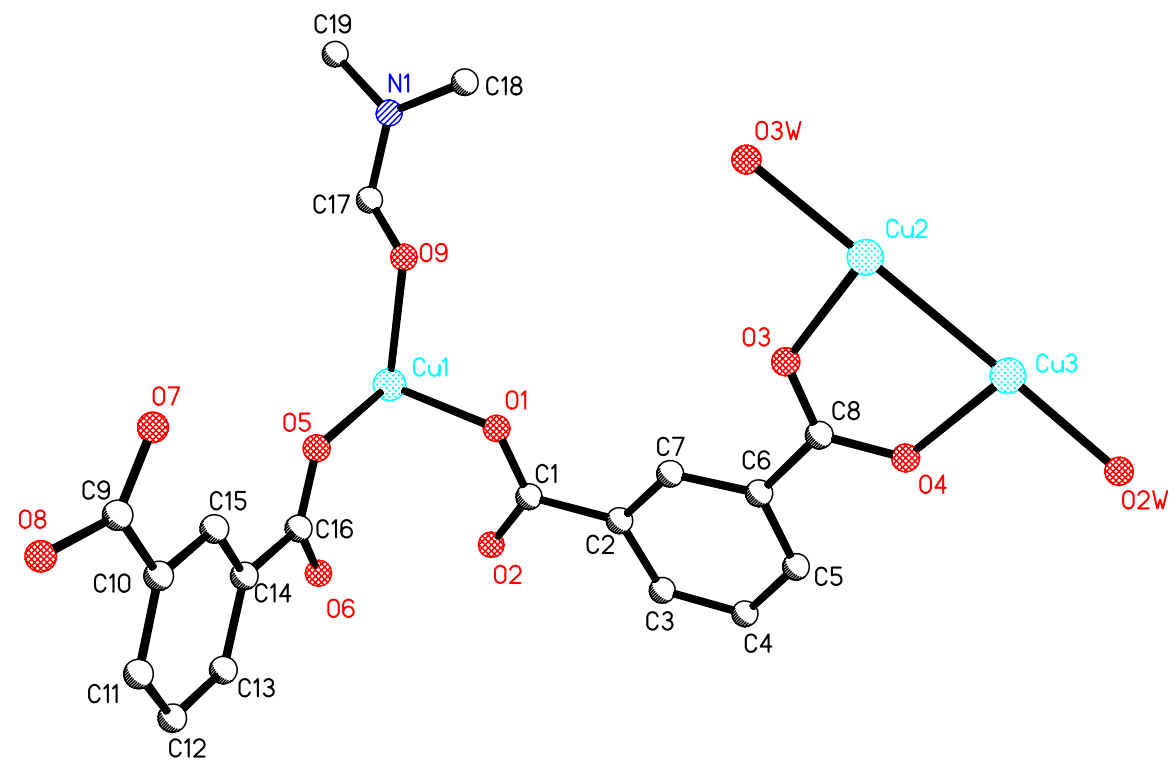

Figure S5. The asymmetric unit in $\mathbf{2} \cdot 4 \mathrm{H}_{2} \mathrm{O}$ excluding lattice water molecules. 


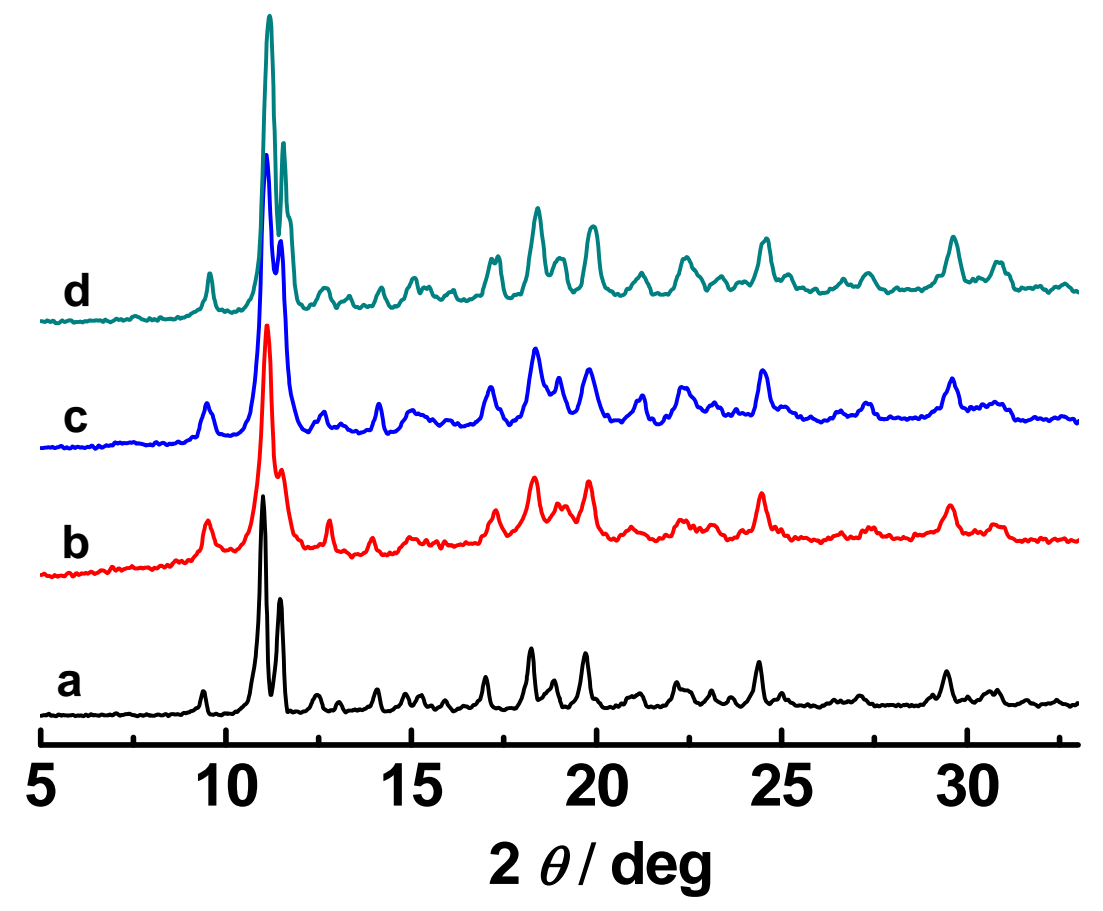

Figure S6. XRPD patterns for as-synthesized $\mathbf{2} \cdot \mathrm{g}$ and samples after sorption measurement of $\mathbf{2} \cdot \mathbf{g}$ measured at room temperature: (a) as-synthesized; (b) after $\mathrm{N}_{2}$ sorption measurement; (c) after methanol sorption measurement; (d) after benzene sorption measurement.

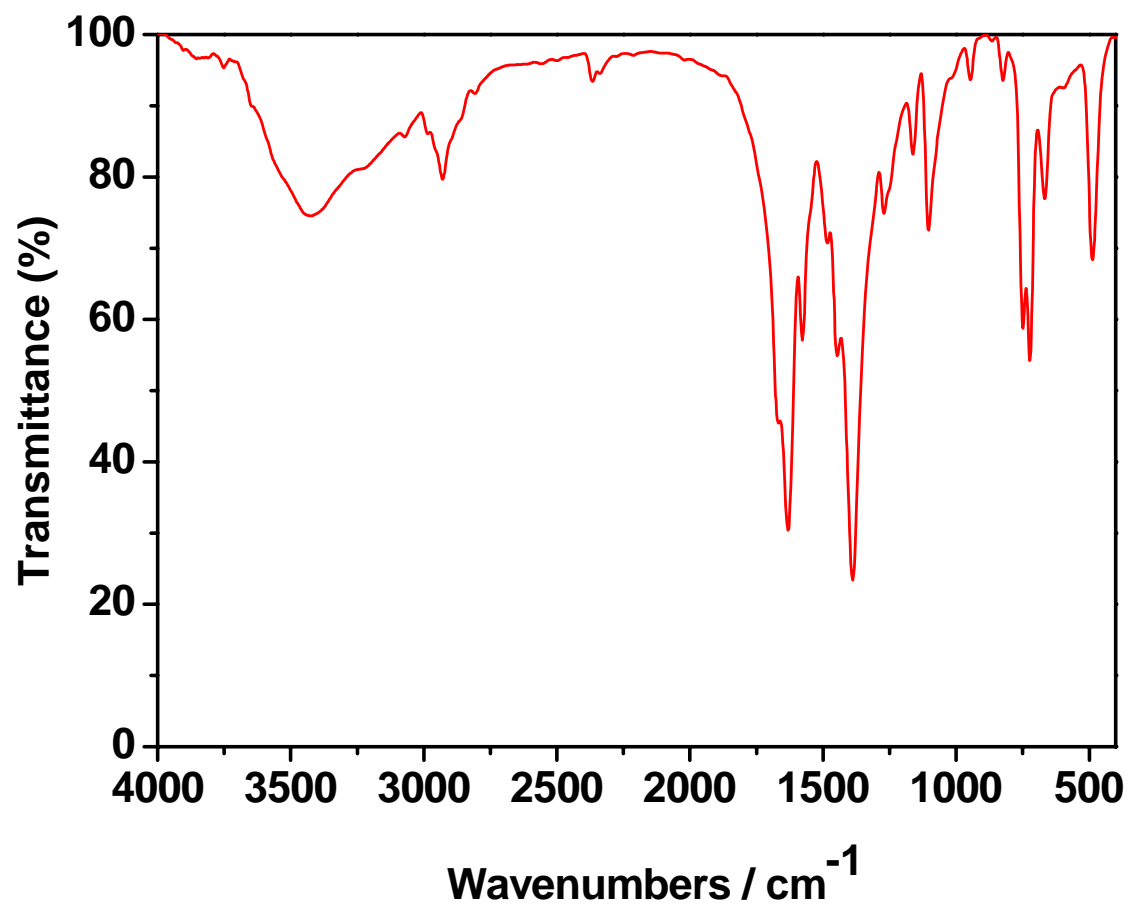

Figure S7. The IR spectrum of $2 \cdot \mathrm{g}$. 


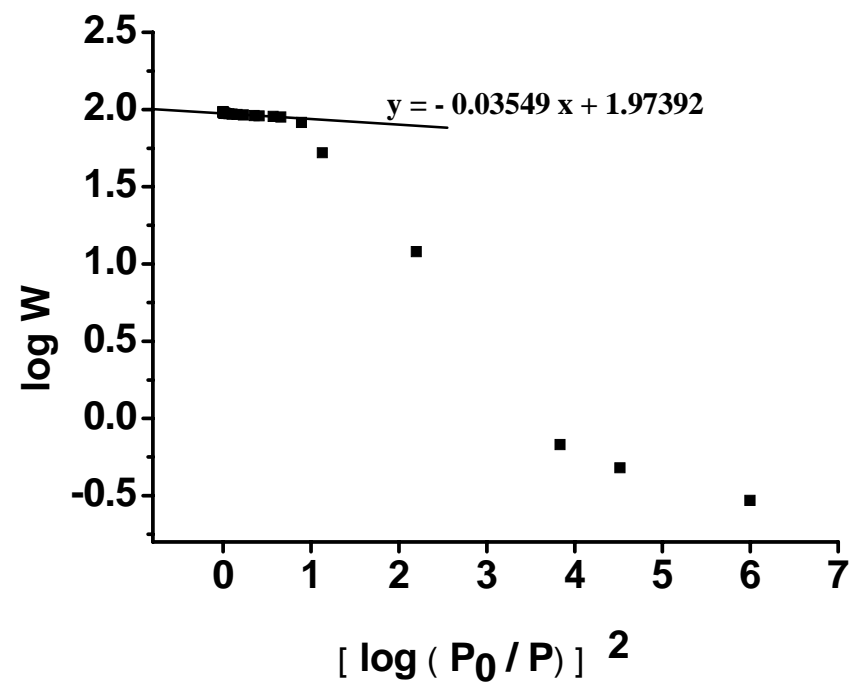

Figure S8. DR plot of $\mathrm{N}_{2}$ adsorption isotherm for solid 2.

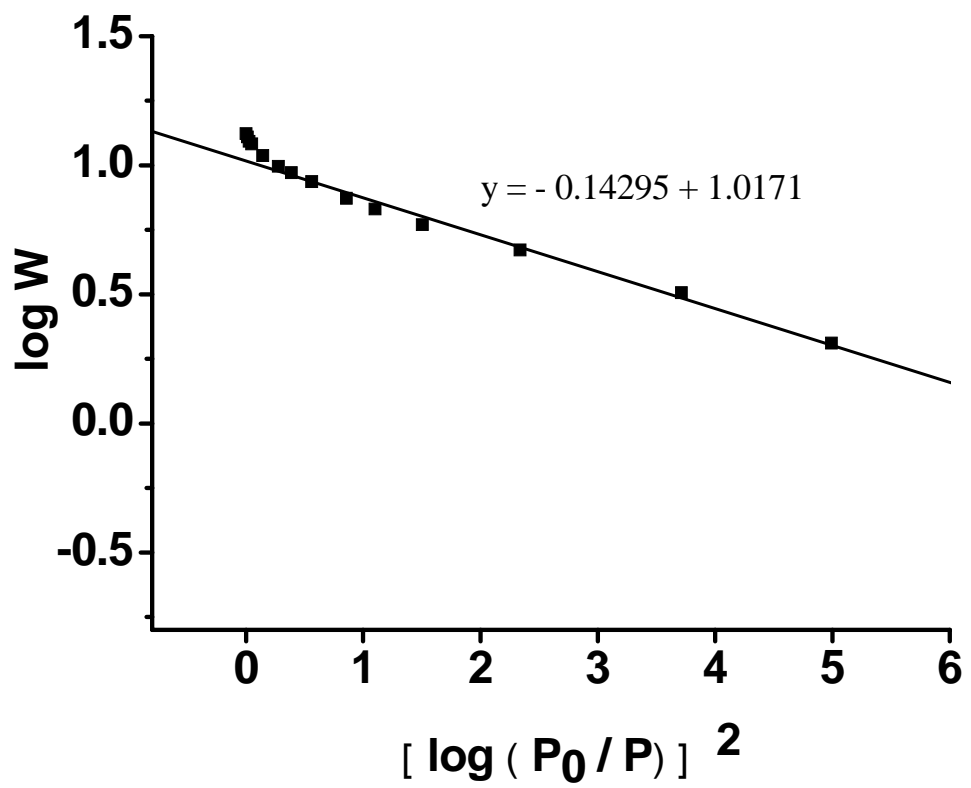

Figure S9. DR plot of $\mathrm{CH}_{3} \mathrm{OH}$ adsorption isotherm for solid 2. 


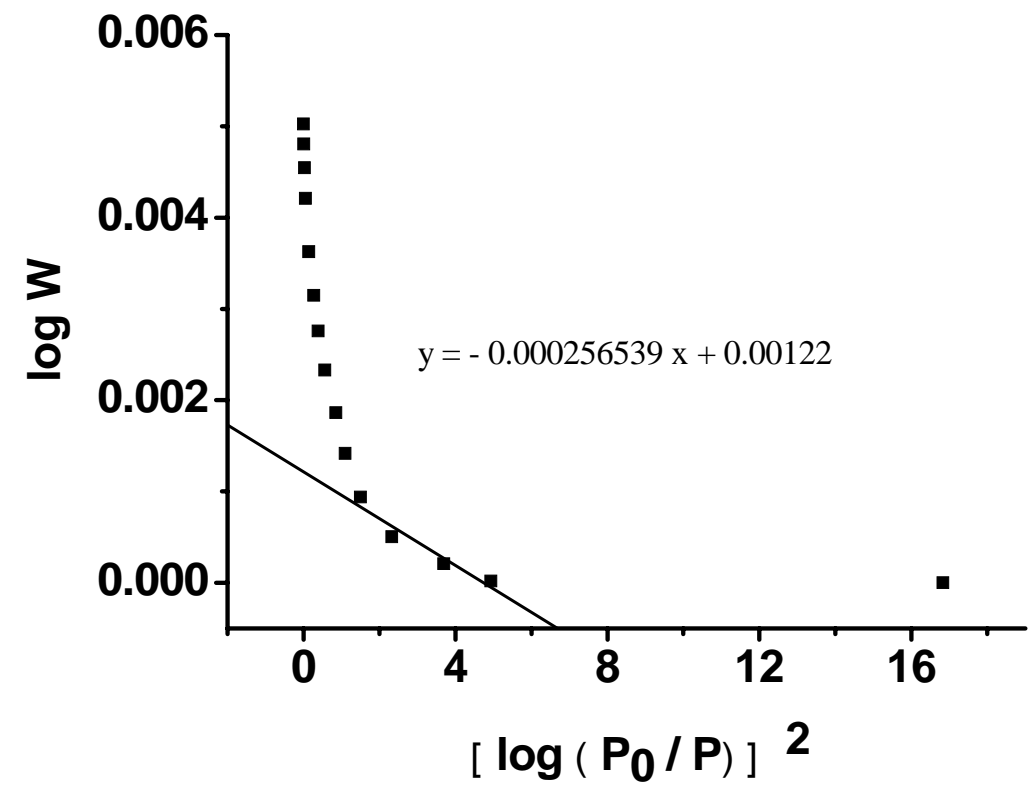

Figure S10. DR plot of $\mathrm{C}_{6} \mathrm{H}_{6}$ adsorption isotherm for solid 2.

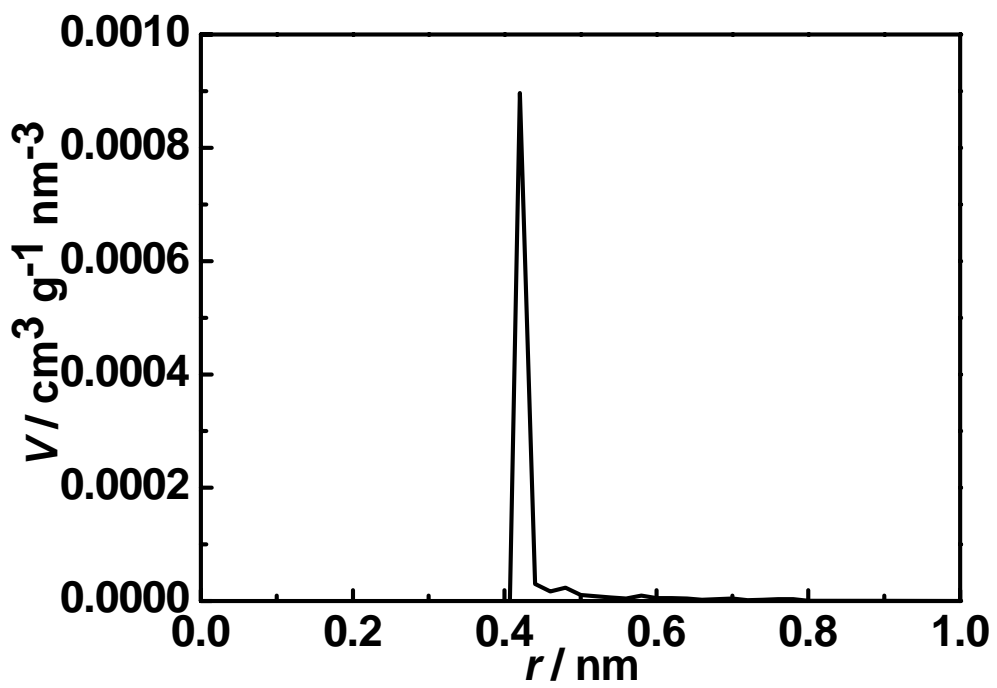

Figure S11. The pore-size distribution for solid 2. 